\title{
Prevalence and distribution of foot lesions in dairy cattle in Alberta, Canada
}

\author{
L. Solano, ${ }^{* 1}$ H. W. Barkema, ${ }^{*}$ S. Mason, ${ }^{*}$ E. A. Pajor, ${ }^{*}$ S. J. LeBlanc, † and K. Orsel* \\ *Department of Production Animal Health, University of Calgary, Calgary, Alberta, Canada, T2N 4N1 \\ †Department of Population Medicine, University of Guelph, Guelph, Ontario, Canada, N1G 2W1
}

\begin{abstract}
The objectives of this cross-sectional study were to determine the prevalence and distribution of foot lesions and associated cow- and herd-level risk factors in dairy cows in Alberta, Canada. Foot lesion data were recorded electronically by 7 hoof trimmers on 28,607 cows in 156 dairy farms from June 2009 to November 2012. Foot lesion prevalence estimates differed between farms that had the whole herd trimmed at once ( $\geq 80 \%$ of lactating cows were trimmed; $\mathrm{n}=69$ farms and 8,020 cows) and farms on which part of the herd was trimmed (selection of cows was determined by farmer and $<80 \%$ of lactating cows were trimmed; $\mathrm{n}=87$ and 20,587 cows). Estimates were consistently higher for the latter likely because farmers presumably prioritized lame cows in partial-herd trims. On farms with whole-herd trims, digital dermatitis was the most common lesion among all housing types, present in 15\% of cows and $94 \%$ of herds. Sole ulcers and white line disease were detected in 6 and $4 \%$ of the cows and 92 and $93 \%$ of herds, respectively. Other infectious and claw horn lesions each affected 1 to $2 \%$ of cows and 62 to $78 \%$ of herds. Intraclass correlation coefficients for hoof trimmers ranged from 0.01 to 0.20 for all lesions, indicating some clustering of recorded lesions by trimmer. Multilevel mixed logistic regression models were constructed (including hoof trimmer as fixed and farm as random effects) for the 3 most frequently identified lesions. Prevalence of digital dermatitis decreased with increasing parity, but this effect interacted with days in milk (DIM); primiparous cows had higher odds of digital dermatitis in mid lactation (100-199 DIM) and late lactation $(\geq 200$ DIM) compared with cows at other stages of lactation. In contrast, prevalence of sole ulcers and white line disease increased with increasing parity; compared with cows in parity 1 , those in parity 4 had 5 or 7 times higher odds of having these lesions,
\end{abstract}

Received January 25, 2016.

Accepted April 16, 2016.

${ }^{1}$ Corresponding author: laurasolanoquesada@gmail.com respectively. Cows in mid lactation and late lactation had higher odds of sole ulcers and white line disease than cows at other stages of lactation, regardless of parity. Digital dermatitis prevalence was 2 times higher in herds housed in barns with access to an exercise area. The odds of sole ulcers and white line disease were $\geq 2$ times higher in cows housed in freestalls than those housed in deep-bedded packs. Therefore, preventive measures for control of digital dermatitis merit emphasis, especially in primiparous cows and on farms with exercise areas. In addition, improving housing environment by providing a deep-bedded area for older cows in mid lactation or late lactation could reduce prevalence of claw horn lesions. We inferred that foot lesion data recorded by hoof trimmers can provide useful information not only to develop effective foot health programs at herd level, but also for disease surveillance and genetic improvement at regional and national levels.

Key words: claw zone, hoof health, claw trimming, lameness

\section{INTRODUCTION}

Lameness is a severe welfare problem in cattle and has a detrimental effect on longevity (Cramer et al., 2009a), productivity (Green et al., 2002), and reproductive performance (Barkema et al., 1994; Garbarino et al., 2004). Consequently, it is among disorders causing the largest economic losses in the dairy industry (Ettema and Ostergaard, 2006). Approximately 90\% of the causes of lameness involve foot lesions (Murray et al., 1996; Shearer and Van Amstel, 2013), although foot lesions do not necessarily result in lameness (Manske et al., 2002b). Regardless of whether foot lesions cause lameness, they have a high impact on animal welfare (Bruijnis et al., 2012) and farm economics. Foot disorders that result in lameness are estimated to cost $\$ 95$ on average, whereas foot disorders that do not cause lameness cost $\$ 18$ per case on average (Bruijnis et al., 2010). In addition, lameness prevalence is often underestimated by dairy producers (Espejo et al., 2006). Therefore, inspection of foot lesions as a routine management practice facilitates earlier identification 
and treatment of lesions, plausibly enhancing herd productivity and welfare (Cramer et al., 2008; Chapinal et al., 2009).

Prevalence of foot lesions varies considerably among farms, regions, and housing systems. For example, when cows are housed in tiestall barns, prevalence of foot lesions is lower than when cows are housed in freestalls (21\% lower in Ontario and $37 \%$ lower in Norway, respectively; Fjeldaas et al., 2006; Cramer et al., 2008). In addition, cow-level prevalence of digital dermatitis ranged from $8 \%$ in Chile to $23 \%$ in Ontario (Cramer et al., 2008; Tadich et al., 2010). Herd-level prevalence of digital dermatitis ranged from 92 to $100 \%$ when cows were housed on concrete flooring, whereas when cows were housed in deep-bedded straw yards, $65 \%$ of herds were free of digital dermatitis (Somers et al., 2003; Cramer et al., 2008).

Each type of lesion has its own pathophysiology and specific risk factors. Foot lesions are commonly categorized according to their etiology into infectious and noninfectious lesions (International Lameness Committee, 2008; Potterton et al., 2012). Infectious lesions include digital dermatitis, interdigital dermatitis, heel horn erosion, and foot rot, whereas the most common noninfectious lesions are sole ulcer, toe ulcer, sole hemorrhage, and white line disease. Infectious lesions usually affect foot skin and are influenced by herd-level factors such as wet and unhygienic floor conditions (Bell et al., 2009), scraping frequency (Cramer et al., 2009b), introduction of dry cows into the milking herd, pasture access, and footbathing frequency (Somers et al., 2005a,b). Noninfectious lesions affect the claw horn, and their occurrence is associated with metabolic and hormonal events around calving that weaken the foot suspensory apparatus (Tarlton et al., 2002), low BCS (Green et al., 2014), toe overgrowth, exposure to hard flooring (Manske et al., 2002a; Somers et al., 2003), and thickness of the digital cushion (Bicalho et al., 2009).

Despite increased awareness of lameness as a problem in North America, we are only aware of 1 epidemiological study to identify prevalence and distribution of foot lesions and associated risk factors (Cramer et al., 2008, 2009b). Understanding the type, frequency, and distribution of foot lesions will provide insight into their epidemiological background and potentially lead to the identification of trends in the presence of foot lesions and whether they change over time. Therefore, objectives of this study were to determine (1) the prevalence and distribution of foot lesions using observations recorded electronically by hoof trimmers, and (2) the association between herd- and cow-level factors and the prevalence of the most frequently identified foot lesions.

\section{MATERIALS AND METHODS}

\section{Data Recording}

Seven of 17 hoof trimmers in Alberta, Canada, agreed to participate in the Alberta Dairy Hoof Health Project, a project developed by Alberta Milk (Edmonton, AB, Canada). The Alberta Dairy Hoof Health Project was designed to collect foot lesion data using a computerized lesion recording system that facilitated routine and consistent data collection. In short, the 7 participating hoof trimmers attended an on-farm workshop demonstration of Hoof Supervisor lesion recording software (KS Dairy Consulting, Dresser, WI). The software was installed on damage-resistant touch screen personal computers with a Microsoft Windows XP operating system. The recording method of Hoof Supervisor enabled differentiation between front and back and left and right feet and between lateral and medial claws. This system also captured the location of lesions in 12 claw and foot zones, using the Claw Lesion Identification in the Dairy Cattle Brochure developed by Zinpro Corporation (D40-08-08-30-07, Zinpro Corporation, Eden Prairie, MN) in cooperation with the International Lameness Committee (2008).

To assist in accurate and consistent identification, Hoof Supervisor permits identification of the cow, foot, and claw (in that order). Once the affected claw is selected, the type of foot lesion can be selected from a list of possible lesions specific to each claw zone. Hoof trimmers received a financial incentive of Can $\$ 1$ per cow for submitted trim data.

Two veterinarians with experience in lameness trained the hoof trimmers to identify foot lesions in a uniform manner during a 1-d hoof health clinic. Digital, colored photographs were used to identify each foot lesion according to the international classification system adopted during the 15th International Conference on Lameness held in Finland (International Lameness Committee, 2008). A guide containing photographs of different levels of foot lesion severity was developed to assist hoof trimmers in consistently scoring lesions. One year after field data collection was in progress, another 1-d hoof health clinic was carried out to review and reinforce identification of foot lesions.

\section{Herd and Cow Selection}

A total of 156 dairy farms located in south and central Alberta, Canada, were enrolled. Data were collected between June 2009 and November 2012. Hoof trimmers recruited their client farms to participate in the study, 
regardless of foot lesion status. Participation was voluntary and at the farmer's discretion. By participating, farmers signed consent forms agreeing to share their trim records and milk records provided by CanWest DHI (Guelph, ON, Canada). The DHI data (parity, DIM, and milk production) from the most recent milk recording test after the hoof trimmer's visit were selected for analyses. Reasons for missing DHI data were that farms dropped out of DHI services (2 farms), cows were sick at milk recording, or failure of producers to report calving dates (Figure 1). Information on housing type was collected by the hoof trimmer. An exercise area was defined as an outdoor, unroofed, soil-floored, enclosed area with access to the dairy barn. On farms with partial-herd trims, selection of cows was done by the farmer. To estimate representativeness of the study, data regarding averages on Alberta dairy farms were obtained from 2012 CanWest DHI data (Canadian Dairy Information Centre, 2016).

\section{Data Management and Statistical Analysis}

Trim data were extracted from Hoof Supervisor backup files and imported into a Microsoft SQL Server database through a custom application written in Microsoft Visual Basic (Microsoft Corp., Redmond, WA). The DHI data, provided by CanWest DHI in the form of fixed-field-length text files, were imported into the database through a second custom Visual Basic application. Farm and hoof trimmer identification data were entered into the database manually. Subsequent data editing and statistical analyses were done using Stata 13.1 (StataCorp, 2013, College Station, TX).

The original data set contained 87,834 cows with data from multiple trimmings (Figure 1). To minimize selection bias introduced by the farmer and repeated observations, prevalence was estimated separately for farms that had the whole herd trimmed at once $(\geq 80 \%$ of lactating cows were trimmed, $\mathrm{n}=69$ farms) and

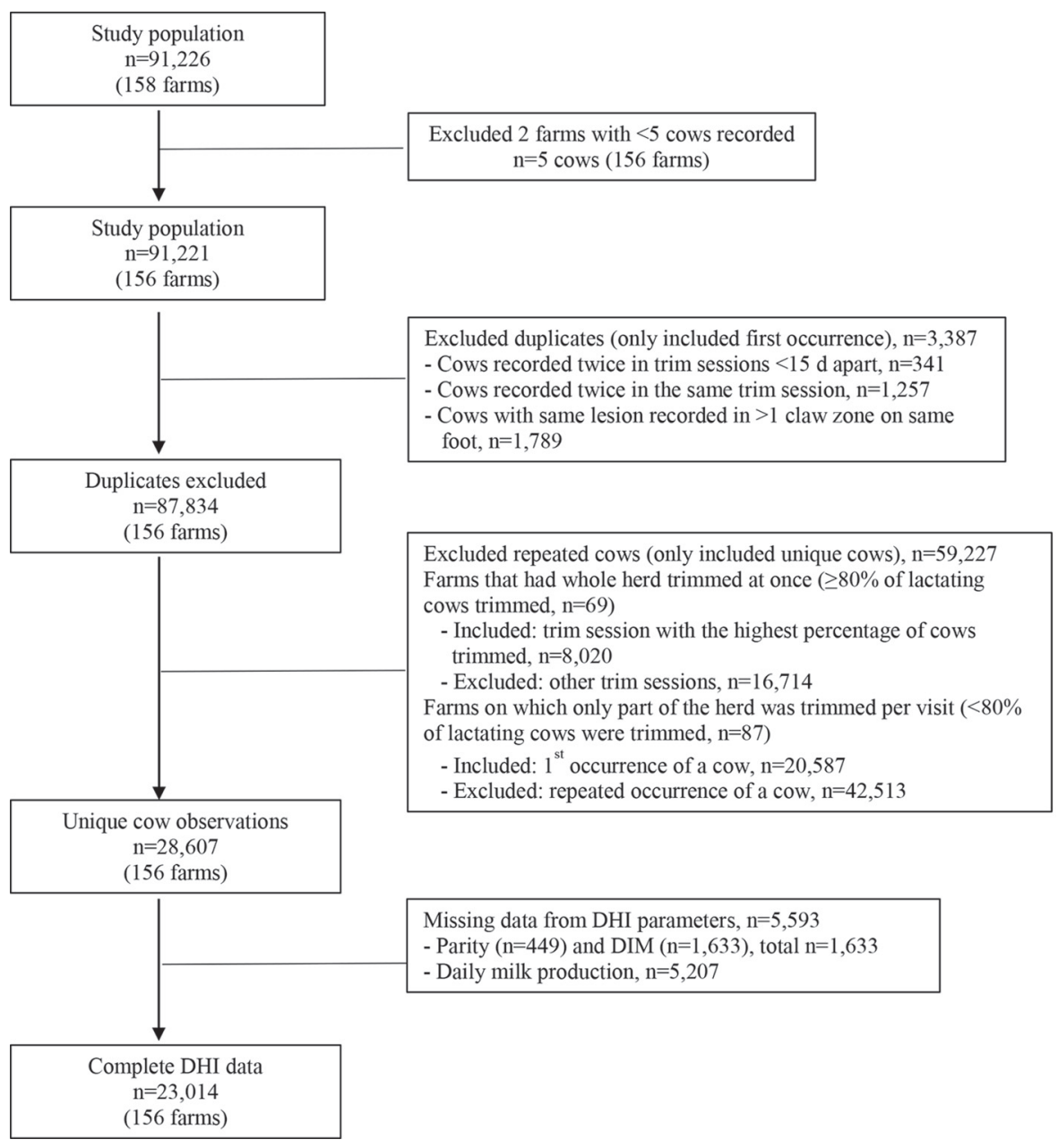

Figure 1. Flowchart of dairy cow study selection process. 
farms on which part of the herd was trimmed $(<80 \%$ of lactating cows were trimmed, $\mathrm{n}=87$ ). The value of $80 \%$ was selected as a cutoff to define a farm with a whole- or partial-herd trim, using logistic regression models. The outcome of interest was the presence of any foot lesion at the cow level. Herd size, housing type, and percentage of lactating cows trimmed per trim session were included as predictors. Various cutoff points (i.e., $60,70,80$, or $90 \%$ of lactating cows trimmed) were tested individually to assess the probability that cows were selected based on presence of foot lesions. Values above $80 \%$ were not associated with the odds of presence of a lesion, suggesting that cows were not selected based on their foot lesion status if $\geq 80 \%$ of lactating cows were trimmed in one session (which could occur over 1 or $3 \mathrm{~d}$ ).

For farms that had the whole herd trimmed, the trim session with the highest percentage of unique cows trimmed was used to calculate foot lesion prevalence at cow and herd levels. Because it is common for a herd to be trimmed over several days, trim sessions that occurred within $15 \mathrm{~d}$ were considered a single event. For farms on which part of the herd was trimmed, cow- and herd-level prevalence was presented for the first occurrence of a cow in the data set. For each type of foot lesion and hoof trimming routine (whole- and partialherd trim), prevalence was calculated as the number of affected animals divided by the total number examined.

Individual cows with duplicate or missing cow identification were removed from the data set (Figure 1). If the same lesion was recorded in 2 different claw zones on the same foot, it was only considered a single occurrence of the lesion. Data were collapsed at the lowest level (foot) on a binary scale. Hoof health status was first collapsed into front and hind limbs, and then into cow. Foot lesions with low frequency $(\leq 1 \%)$ were collapsed based on their pathophysiology into "other lesions" (these included thin sole, corkscrew claw, and axial, horizontal, and vertical fissures) or "other infectious lesions" (heel erosion, interdigital dermatitis, and foot rot). A cow was considered to have multiple lesions if the same type of lesion affected different feet or if different types of lesions affected the same or different feet.

Data were structured at 4 levels: hoof trimmer, herd within-hoof trimmer, cow within-herd, and foot withincow. Two analyses were performed. In the first analysis, intraclass correlation coefficients (ICC) were used to estimate proportion of correlation of cows within a herd and of observations within a hoof trimmer. The ICC were calculated modeling each foot lesion separately, including hoof trimmer and herd as random effects. In the second analysis, associations between the most prevalent foot lesions and cow- and herd-level predictor variables were assessed, using multilevel mixed logistic regression modeling with presence of each foot lesion at the cow level as the outcome of interest and using a backward elimination process. All variables associated with the outcome $(P<0.10)$ in the univariable analyses were subsequently included in multivariable modeling. Variables significant at $P<0.05$ were retained in the final model. For this analysis, presence of other foot lesions were included as predictors and classified into "claw horn lesions" (sole and toe ulcer, sole hemorrhage, and white line disease), "other infectious lesions" (interdigital dermatitis, foot rot, and heel erosion), and "other lesions" (thin sole, corkscrew claw, and horizontal, vertical, and axial fissures) (Chapinal et al., 2013). Digital dermatitis and interdigital hyperplasia were not grouped into one category; instead, they were tested independently as predictors. Additionally, if confounding was present (i.e., removal of any variable resulted in a 30\% change in the estimate of any other significant predictor), that variable was also retained in the final model. Two-way interactions (e.g., parity and DIM, herd size, and housing type) were tested among the significant predictors in the main effects model. Farm was included as a random effect. Hoof trimmer and hoof trimming routine (whole- vs. partial-herd trims) were forced into the final regression model as fixed effects because of differences in foot lesion prevalence estimates between farms with partial- versus wholeherd trims. Model comparison among all multivariable models was based on Akaike's information criterion, and the model with the lowest Akaike's information criterion was considered the best model.

\section{RESULTS}

The sample of farms $(n=156)$ was representative of the average dairy farm in Alberta in terms of herd demographics (median proportion of cows in third parity or higher: study herds vs. entire province $=36$ and $37 \%$, respectively), median annual culling rate (38 and $38 \%$ ), breed (breed composition of Holstein-Friesian $=97$ and 98\%), and housing type (freestall barns = 83 and $81 \%$ ). Farms on which the whole herd was trimmed were representative of the average Alberta farm in terms of herd size, whereas farms where the herd was partially trimmed had a larger herd size (243 cows) than the average Alberta farm (provincial average herd size $=138$ cows). Farms on which the herd was partially trimmed had a shorter median interval of hoof trimming sessions (2 mo) than farms on which the whole herd was trimmed (herd size $=139$ cows and hoof trimming interval $=6 \mathrm{mo}$ ). Median parity of cows trimmed was 2 in herds in which the whole herd was trimmed vs. 1 in partially trimmed herds (Table 1 ). 


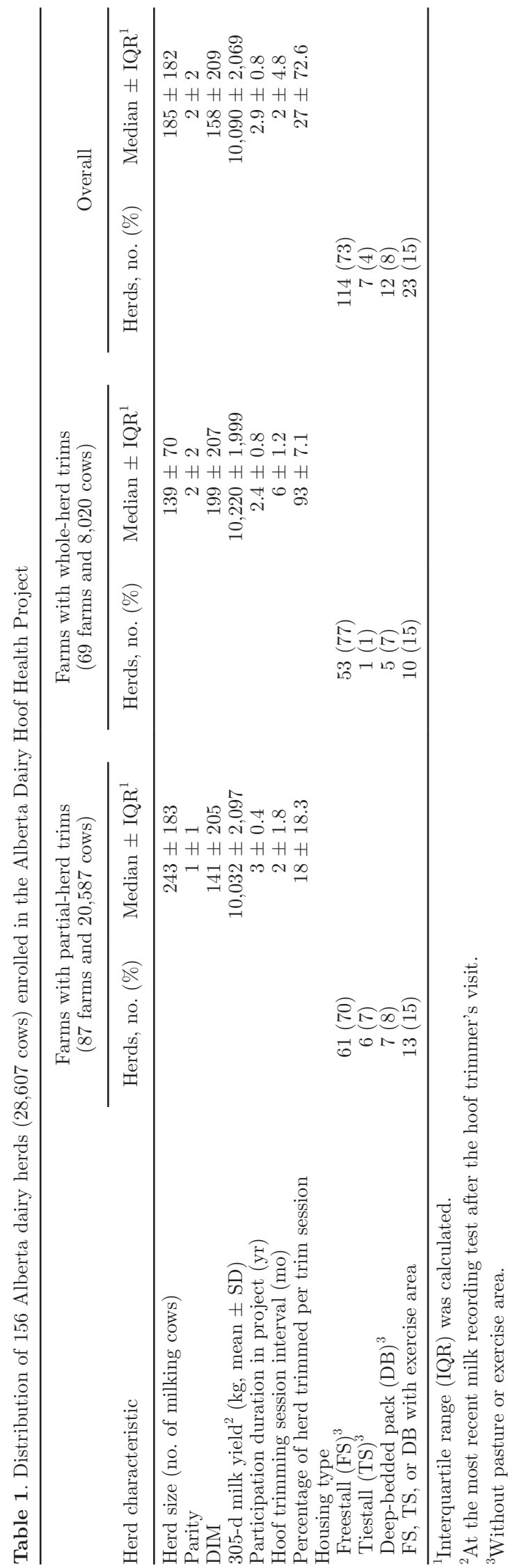

Hoof trimmers recorded lesions on 28,607 unique cows over a 3.5-yr interval (Figure 1). A total of 20,587 and 8,020 cows were included from farms where the herd was partially trimmed and where the whole herd was trimmed, respectively. Complete observations on parity and DIM were obtained from 26,974 cows and complete observations on parity, DIM, and milk production were obtained from 23,014 cows.

\section{Prevalence and Distribution of Foot Lesions}

Thirty-six percent of cows had at least one foot lesion. Of these, 26,9 , and $1 \%$ of cows had 1,2 , and $\geq 3$ legs affected, respectively. Lesion prevalence was higher in rear feet than in front feet among all types of foot lesions; however, claw horn lesions were more common in front feet compared with digital dermatitis and interdigital hyperplasia. In that regard, 73 to $81 \%$ of claw horn lesions occurred in the rear feet, whereas $94 \%$ of digital dermatitis lesions occurred in the rear feet. In addition, claw horn lesions were more commonly found in the medial claw of front feet than in the lateral claw of rear feet (Table 2). The greatest number of lesions occurred in zone $10(38 \%)$, followed by zone $4(20 \%)$ and zone $3(13 \%)$, and up to $4 \%$ of lesions occurred simultaneously in $>1$ zone (Figure 2).

On farms with partial-herd trims, foot lesion prevalence estimates were higher (both overall and foot lesion-specific, except sole hemorrhage) than on farms with whole-herd trims (Table 3). Because herds where a partial-herd trim was conducted were less representative of dairy herds in Alberta and a purposive and younger selection of cows was observed in these herds, we chose to focus on farms with whole-herd trims. On these farms, $28 \%$ of the cows had at least one lesion and $5 \%$ of cows had multiple lesions. Digital dermatitis was the most prevalent lesion ( $15 \%$ of cows), followed by sole ulcer $(6 \%)$ and white line disease $(4 \%)$. Withinherd prevalence varied greatly; notwithstanding, for all lesions, some herds had a prevalence of zero (Table 3 ). For example, in 6,8 , and $7 \%$ of the herds, no cows were recorded with digital dermatitis, sole ulcers, and white line disease, respectively. Furthermore, 6 and $2 \%$ of cows with digital dermatitis also had sole ulcers and white line disease, respectively, whereas $45 \%$ of cows with interdigital hyperplasia also had digital dermatitis. Presence of foot lesions varied among housing types.

The 7 hoof trimmers recorded data on a median of 19 herds each (range: 9-40). The percentage of farms with whole-herd trims varied among hoof trimmers (range: 8-100\%). Estimated ICC for hoof trimmers did not exceed 0.20 and were lower than farm-level ICC among all foot lesions (Table 4). 
Table 2. Distribution of foot lesions [no. (\%)] by foot and claw per cow $(\mathrm{n}=28,607)$ on 156 Alberta, Canada, dairy farms

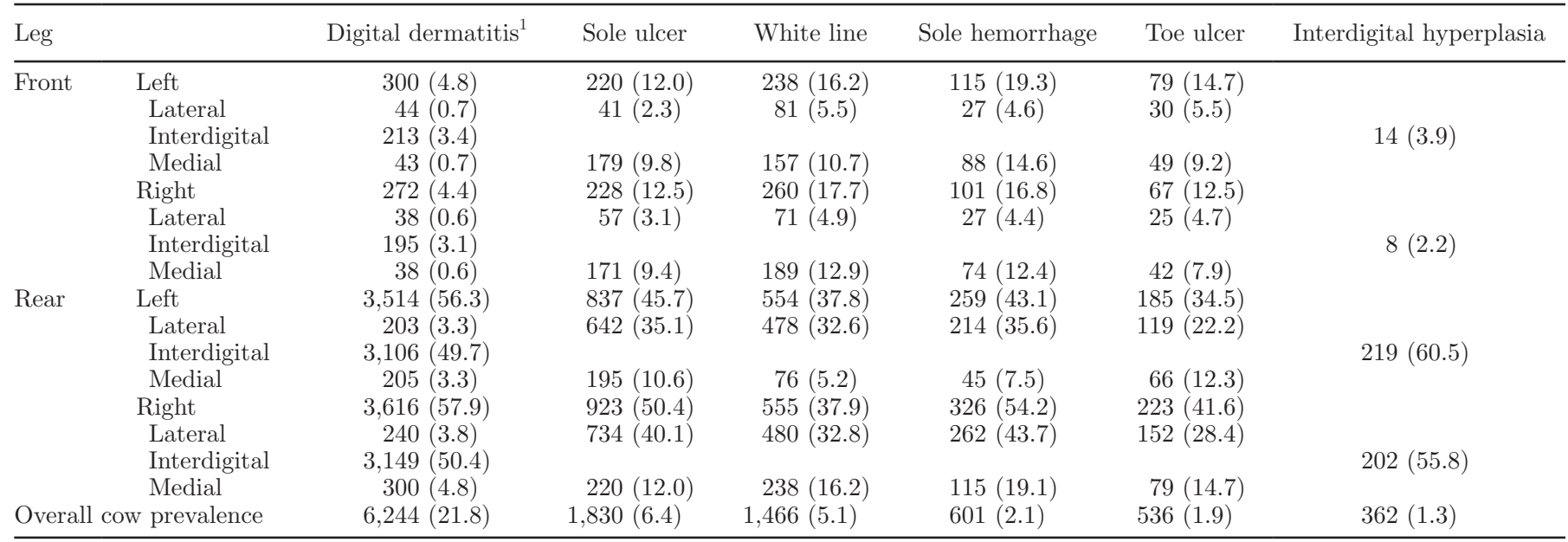

${ }^{1}$ Percentages add to $>100 \%$ due to simultaneous occurrence of lesions in $>1$ claw per leg.

\section{Risk Factors for Foot Lesions}

For nonlactating heifers examined $(\mathrm{n}=256), 23,3$, and $2 \%$ had digital dermatitis, sole ulcers, and white line disease, respectively, whereas 21,5 , and $6 \%$ of dry cows $(n=1,044)$ had these lesions. All foot lesions had significant associations with parity and DIM of cows at the time of hoof trimming (Figure 3a, b, c). The proportion of cows with digital dermatitis decreased with increasing parity $(P=0.001)$, but this effect differed for varying stages of lactation. In that regard, primiparous cows had a higher prevalence of digital dermatitis in mid lactation (100 to 199 DIM) and late lactation ( $\geq 200$ DIM), whereas multiparous cows had a higher prevalence of digital dermatitis at peak lactation (45-99 DIM). The proportion of cows with sole ulcers or white line disease increased with increasing parity (highest $P=0.003)$. Fresh cows $(\leq 44 \mathrm{DIM})$ and cows at peak lactation had a lower prevalence of sole ulcers or white line disease than cows in mid lactation or late lactation (Table 5 and Figure 3). Cows with interdigital hyperplasia had 4 times greater odds of having digital dermatitis. Cows with white line disease, toe ulcers, or sole hemorrhages had higher odds of having sole ulcers. The odds of white line disease were 3.5 times higher in cows with other claw horn lesions such as thin sole, corkscrew claw, and horizontal, vertical, and axial fissure (Table 5).

At the herd level, the prevalence of digital dermatitis was 2 times higher in barns with access to an exercise area than in freestalls without access to an exercise area (Table 5). The odds of sole ulcers and white line disease were higher in cows housed in freestalls without access to an exercise area than for those housed in deepbedded packs. The prevalence of digital dermatitis was
2 times higher in herds with $>100$ cows than in smaller herds (Table 5).

\section{DISCUSSION}

Compared with other studies conducted in Canada and Europe, our study included the largest sample of cows used to investigate (1) prevalence of foot lesions in dairy cows, and (2) distribution of foot lesions by claw zone. Digital dermatitis was by far the most common foot lesion, followed by sole ulcers and white line disease. The main risk factors associated with these 3 most frequently recorded lesions included parity and DIM, presence of interdigital hyperplasia and other claw horn lesions, access to an exercise area, and housing type.

Selection of cows for trimming determined by the farmer was a potential source of bias for overall prevalence estimation of foot lesions as well as lesion-specific prevalence. To address this potential selection bias, herd- and cow-level prevalence of foot lesions was estimated separately for whole-herd trims and herds that were partially trimmed. Prevalence was consistently higher for the latter herds. This was expected because it seemed likely that farmers prioritized lame cows in partial-herd trims. Therefore, farms with whole-herd trims were likely less biased by cow selection and had more accurate prevalence estimates than partial-herd trims because most of the herd was evaluated. Farms with whole-herd trims were also representative of farms in Alberta in terms of herd size (Solano et al., 2015), in contrast to farms with partial-herd trims. For these reasons and for the purpose of this discussion, we focused on prevalence of foot lesions on farms that had the whole herd trimmed. Notwithstanding, neither 
study farms nor cows within farm were randomly selected, and only farms with routine hoof trimming were selected. Thus, study farms may possibly represent a biased sample with superior management practices for lameness reduction.

The study findings regarding the distribution of foot lesions within feet and claw zone support a body of knowledge about the role of anatomy, gait, and weightbearing dynamics in the pathogenesis of foot lesions (Toussaint Raven, 1985; Greenough, 2007; Shearer and Van Amstel, 2013). It was not surprising to find most of the claw horn lesions affecting the lateral hind claws and lesions occurring in their typical anatomical site. However, misdiagnosis of lesions may occur when they are in an early stage or at an advanced stage. For example, early-stage toe ulcers in zone 1 could be difficult to differentiate from white line disease in the same zone, which may explain the high prevalence of toe ulcers occurring in zone 1 in our results (Greenough, 2010). Furthermore, information on the prevalence of lesions not occurring in the typical claw zone is very valuable because it can be an indicator of underlying management or environmental factors affecting that zone. For instance, thin sole toe ulcers occurring in zone 5 near
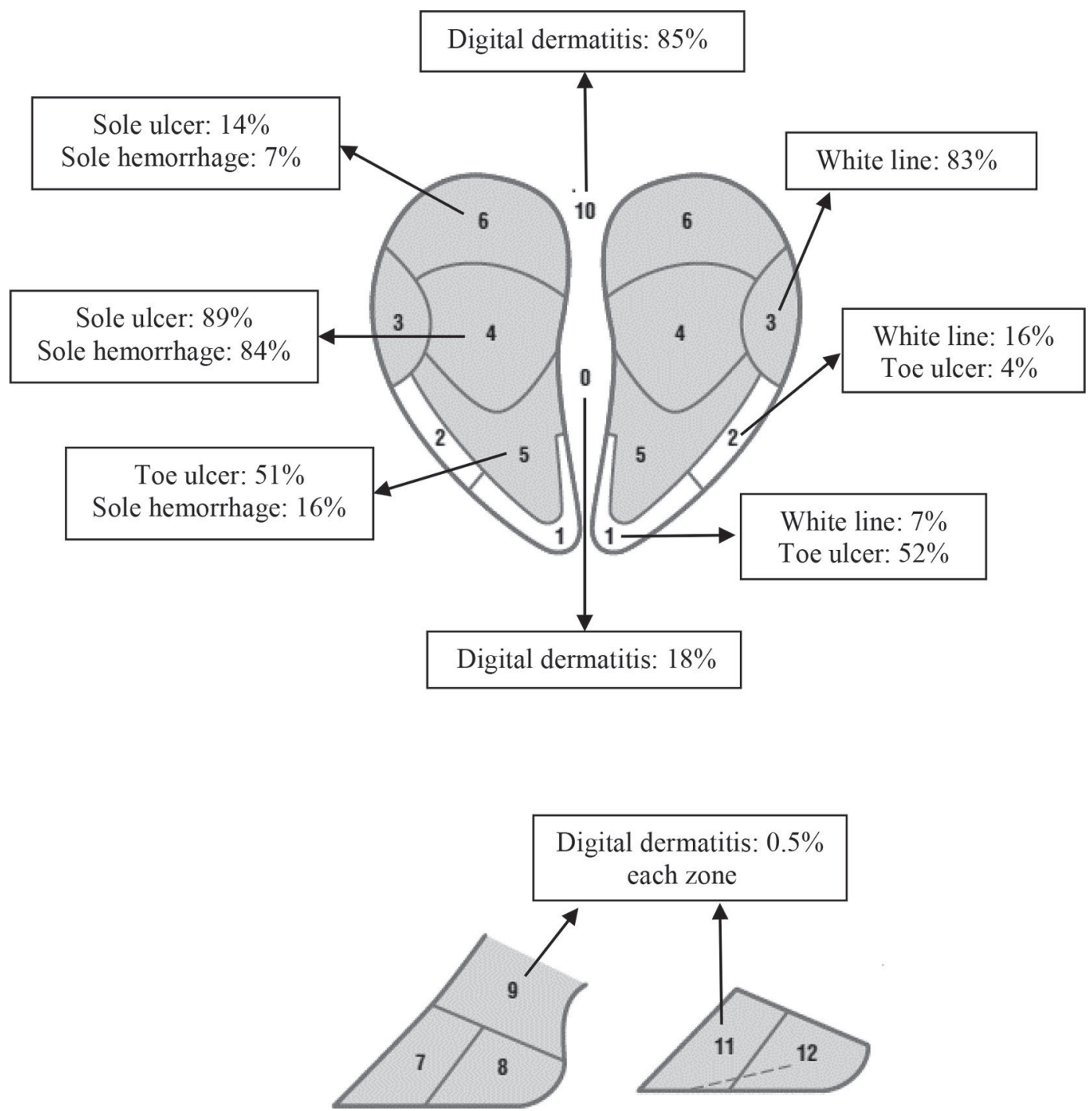

Figure 2. Claw zones affected by each type of the most common foot lesions in 28,607 cows on 156 Alberta, Canada, dairy farms. Percentages indicate the percentage of each type of lesion occurring in a specific claw zone; percentages add to $>100 \%$ due to simultaneous occurrence in $>1$ claw zone. Three percent of sole ulcers occurred simultaneously in zones 4 and 6 . Three, 2 , and $1 \%$ of sole hemorrhages occurred simultaneously in zones 4 and 5; 4 and 6; and 4, 5, and 6, respectively. Four percent of digital dermatitis occurred simultaneously in zones 0 and 10 ; zone 11 corresponds to the anterior interdigital cleft. One, 1, 1, and $2 \%$ of white line lesions occurred simultaneously in zones 1 and $2 ; 1$ and $3 ; 1,2$, and 3 ; and 2 and 3, respectively. One, 4, and 1\% of toe ulcers occurred simultaneously in zones 1 and 2, 1 and 5, and 1, 2, and 5, respectively. Foot lesion identification used was developed by International Lameness Committee (2008) in cooperation with Zinpro Corporation (Eden Prairie, $\mathrm{MN})$. Figure courtesy of Zinpro Corporation (Eden Prairie, MN). 


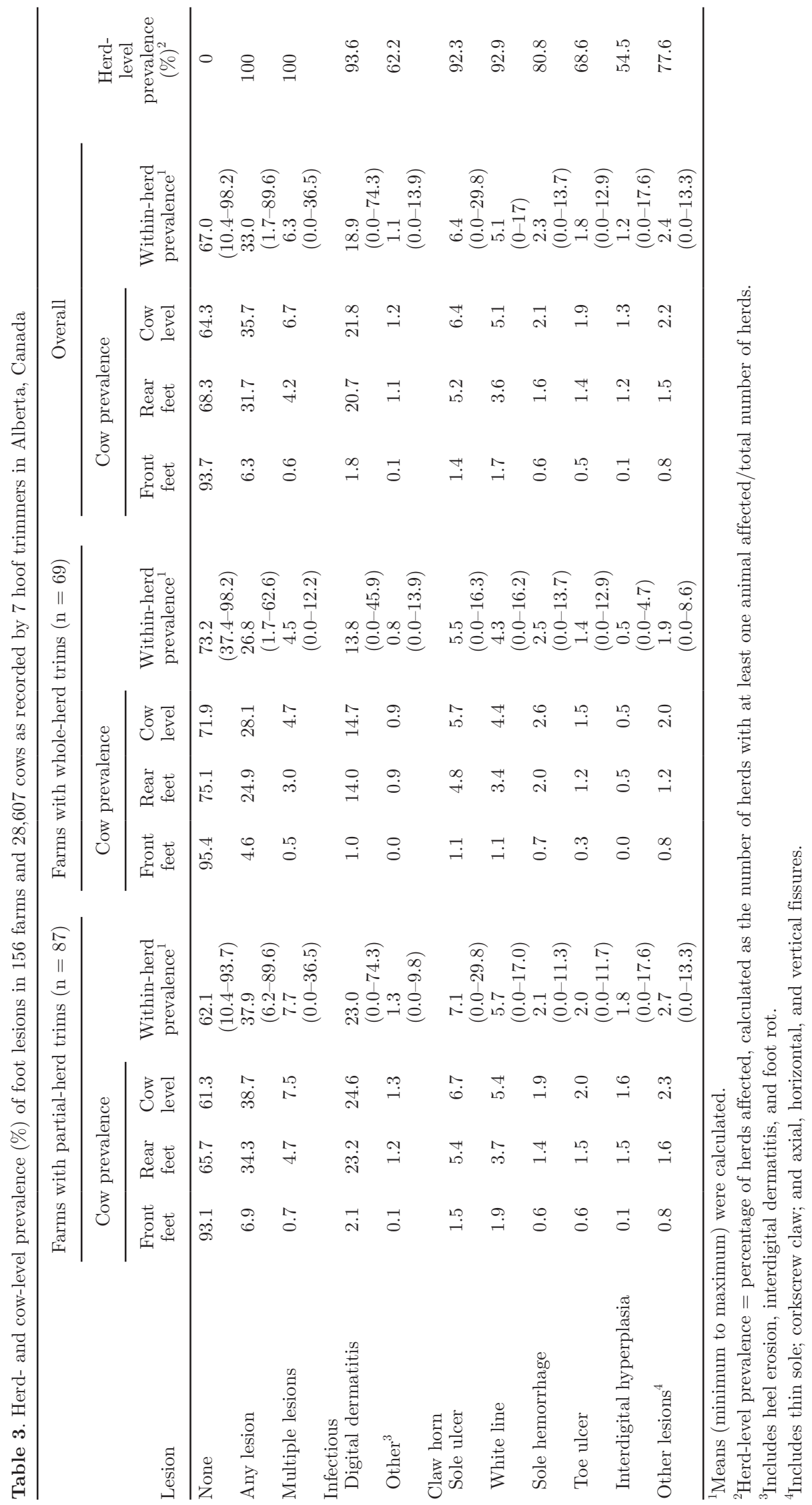


SOLANO ET AL.

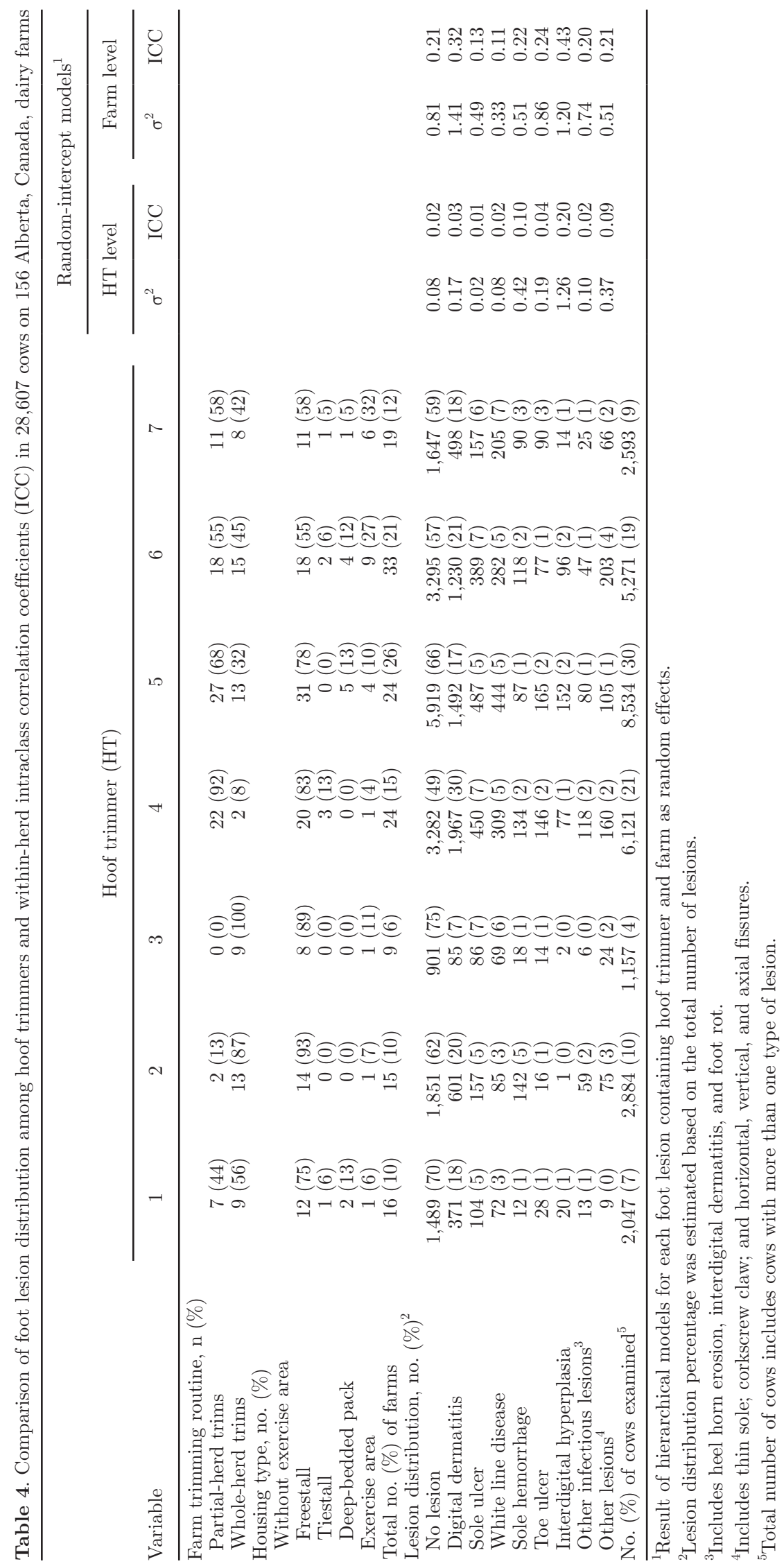


the junction of zones 1 and 2, can be associated with excessive foot wear from abrasive flooring (Sanders et al., 2009; Shearer et al., 2015). Additionally, white line disease occurring in zone 1 instead of the typical zone 3

(a)

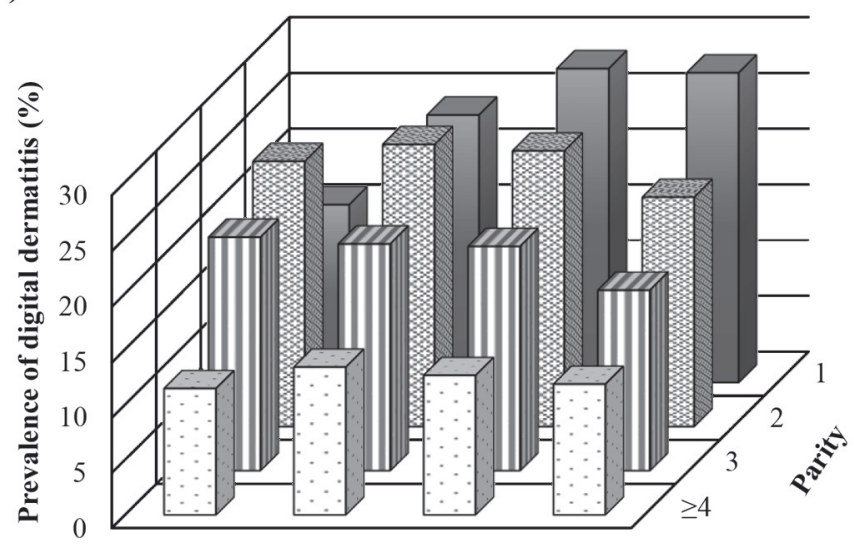

(b)

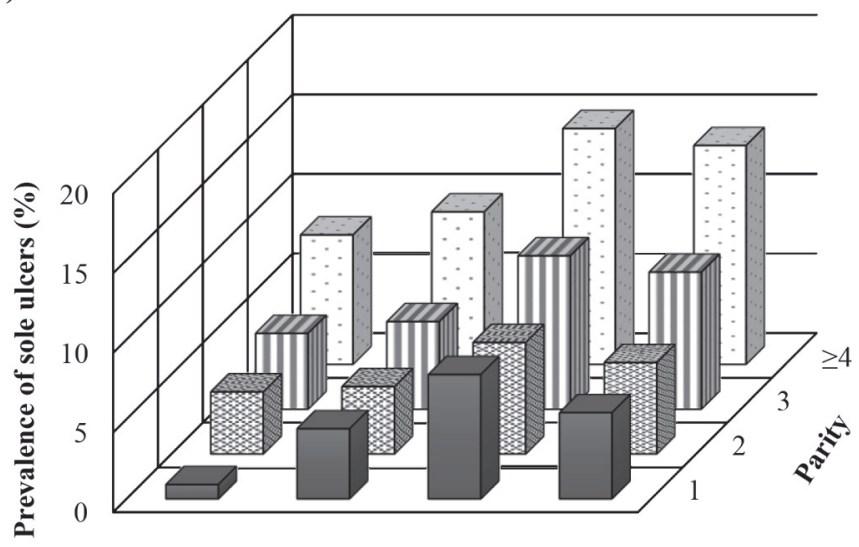

(c)

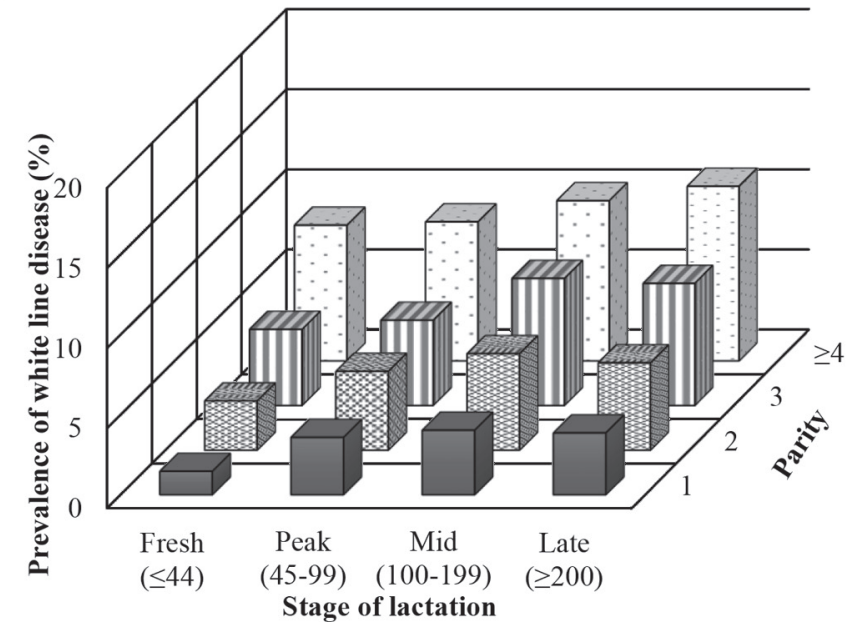

Figure 3. Percentage of dairy cows with (a) digital dermatitis, (b) sole ulcers, and (c) white line disease by parity and stage of lactation. can be associated with inappropriate trimming (Shearer and van Amstel, 2008), and sole hemorrhages or ulcers occurring in zone 6 instead of the typical zone 4 can be associated with perching due to short stalls. Thus, knowledge on lesion zone location allows for targeted foot health programs and recovery follow-up, and from a communication standpoint, it helps in standardizing lesion identification and diagnosis among employees, hoof trimmers, researchers, and veterinarians (DeFrain et al., 2013).

On farms with whole-herd trims, the prevalence of $28 \%$ of cows with $\geq 1$ foot lesion reported in this study seemed comparable to that reported in tiestalls in Ontario (26\%; Cramer et al., 2008), but lower than findings in freestalls in Ontario (47\%; Cramer et al., 2008), Norway (40\%; Fjeldaas et al., 2006), Sweden (72\%; Manske et al., 2002b), and the Netherlands (80\%; Somers et al., 2003). As in other studies, digital dermatitis was the most common lesion. The $15 \%$ prevalence of digital dermatitis reported in this study seemed lower than in freestalls in Ontario (23\%; Cramer et al., 2008) and the Netherlands (21\%; Holzhauer et al., 2006b). Unfortunately, the stage of digital dermatitis lesions was not recorded (lesions were only noted as present or absent). Regardless, infectious lesions were the most prevalent lesion and careful attention should be paid to the efficacy and implementation of preventive measures for their control.

The prevalence of sole hemorrhage $(3 \%)$ and other infectious lesions (1\%) on farms with whole-herd trims was notably lower than estimates from other studies. Reports on the prevalence of sole hemorrhage and heel erosion in other studies ranged from 11 to $39 \%$ and from 8 to $41 \%$, respectively (Manske et al., 2002b; Holzhauer et al., 2006a; Cramer et al., 2008). It is possible that minor or slight manifestations of these common foot lesions without a clear effect on lameness were generally underreported. This was supported by the prevalence of sole hemorrhage being lower for farms with partialherd trims compared with whole-herd trims, suggesting that cows with hemorrhages were not likely to be lame and therefore not selected for trimming. Conversely, prevalence estimates for lesions associated with lameness, such as sole ulcers and white line disease (close to $5 \%$ each) were similar to other reports (close to $9 \%$ each, Manske et al., 2002b; Cramer et al., 2008). The low prevalence of other lesions such as foot rot was not surprising because of the cross-sectional nature of the present study and because those lesions are characterized by acute onset of lameness and rapid treatment (Toussaint Raven, 1985). Additionally, wet pasture conditions, which are not common in Alberta's dairy management systems, are a predisposing factor for foot rot (Greenough, 2007). 


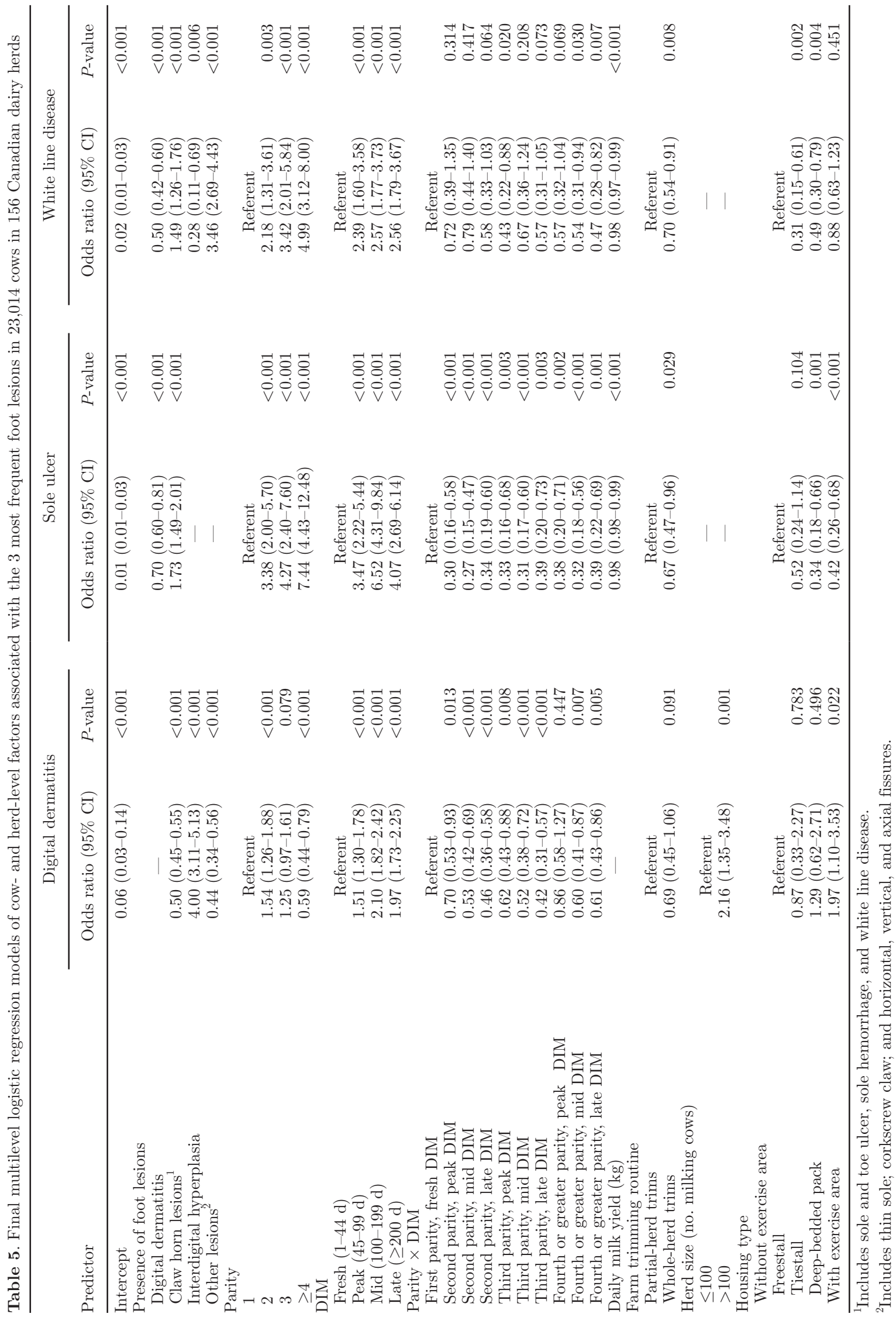


Apparent differences in foot lesion prevalence estimates among countries could be the consequence of factors known to affect prevalence, such as access to pasture (e.g., in the Netherlands $89 \%$ of cows had daily access to pasture and in Norway and Sweden close to $80 \%$ of the study herds were at pasture for $>2$ mo; Manske et al., 2002a; Sogstad et al., 2005; Holzhauer et al., 2006b) and flooring (e.g., in the Netherlands, cows in deep-bedded straw yards had the lowest prevalence of foot lesions; Somers et al., 2003). Additionally, differences in foot lesion estimates could also be a consequence of cow selection. For example, selection of cows in Ontario was done by the farmer (Cramer et al., 2008), whereas in some European studies the whole herd was examined (Manske et al., 2002b; Holzhauer et al., 2006b).

The odds of digital dermatitis decreased with increasing parity, whereas the odds of all other claw horn lesions increased with increasing parity, consistent with other studies (Manske et al., 2002a; Holzhauer et al., 2006b; Barker et al., 2009). This association could be one of the reasons for the higher prevalence of digital dermatitis on farms with partial-herd trims because $54 \%$ of cows presented for trimming in these farms were primiparous compared with $38 \%$ in whole-herd trims. The high prevalence of digital dermatitis in fresh primiparous cows in the present study, suggests that infection starts before calving; therefore, an appropriate and separate nonlactating heifer rearing environment should be a key consideration for effective management of digital dermatitis (Laven and Logue, 2007; Holzhauer et al., 2012). In agreement with Somers et al. (2005a) and Holzhauer et al. (2006b), we found that cows' immunity increases as parity and lactation stage increase and prevalence of digital dermatitis slowly decreases. In the present study, second-parity cows that were fresh or in peak lactation had a higher prevalence of digital dermatitis at the time of trimming compared with primiparous cows that were in the same stage of lactation, similar to a report by Holzhauer et al. (2006b). This finding could be because primiparous cows were affected later in lactation due to a higher infection pressure from prolonged exposure to wet conditions in the lactating barn. In addition, factors related to management of dry cows (e.g., absence of foot bathing) could be more detrimental for primiparous than for multiparous cows, which may explain the high prevalence of digital dermatitis until mid lactation of second-parity cows. However, results on lesion occurrence by stage of lactation should be interpreted with caution because the true onset of lesions is unknown.

The high odds of claw horn lesions for older cows $(\geq 3$ parity) in mid and late lactation at the time of trimming, was comparable to other studies (Manske et al., 2002a; Holzhauer et al., 2008; Barker et al., 2009). This outcome could be explained by a higher risk of recurrence and decreased horn quality due to more prolonged exposure to hard surfaces and external trauma, and to effects of hormonal and metabolic changes around calving, claw horn wear, and trauma (Cook and Nordlund, 2009). It is important to highlight that the use of pasture for lactating cows is not common in Alberta, although the majority of farms manage dry cows on pasture or deep-bedded straw yards. These surfaces are known to benefit hoof health and may provide cows a period of recovery from lameness (Hernandez-Mendo et al., 2007). Nevertheless, the high prevalence of claw horn lesions in mid and late lactation indicates that these become apparent at this stage; however, this observation does not necessarily mark the true onset of lesions at this stage of lactation.

The association between digital dermatitis and interdigital hyperplasia was consistent with other studies (Manske et al., 2002b; Holzhauer et al., 2006b). In agreement with those authors, we suggest that development of interdigital hyperplasia can be a response to chronic irritation of the interdigital skin from poor hygiene and infectious foot lesions. Associations between sole ulcers or white line disease and other claw horn lesions support the theory of common pathogenesis of claw horn disruption lesions (Bicalho and Oikonomou, 2013), and these associations were comparable to conclusions in other studies (Manske et al., 2002b; Holzhauer et al., 2008).

Prevalence of digital dermatitis was higher on farms with access to an exercise area. Studies have differed on the relationship between access to an exercise area and risk of digital dermatitis. A beneficial effect of an exercise area outside the barn on digital dermatitis was reported in freestall barns (Haufe et al., 2012), whereas other reports indicated a detrimental effect in tiestall barns (Cramer et al., 2009b). Although specific characteristics of exercise areas were not recorded, a possible explanation for this increased prevalence was wet and unhygienic conditions of these areas. Prevalence of claw horn lesions was lower in cows housed in deep-bedded packs, consistent with other studies (Somers et al., 2003). Perhaps this association was due to exposure to a softer walking surface (Cook and Nordlund, 2009). We inferred that improvements in footbath management, cleanliness, and a drier environment on farms with exercise areas could decrease digital dermatitis prevalence. In addition, providing a deep-bedded pack area for cows at high risk (older cows in mid or late lactation) could reduce prevalence of claw horn lesions.

This was apparently the first epidemiologic study to report foot lesion prevalence and distribution data collected electronically by hoof trimmers, rather than using 
handwritten reports (Manske et al., 2002b; Fjeldaas et al., 2006; Cramer et al., 2008). To achieve accuracy and consistency of data recording and subsequent analyses, researchers have created case definitions and standardized data collection (Kelton et al., 1998), whereas hoof trimmers are usually not as detailed and precise in this process. Notwithstanding, data on foot lesions collected by hoof trimmers are of great value, owing to the large number of cows and herds typically inspected (Capion et al., 2008). Electronic record keeping is convenient from a practical perspective because it allows hoof trimmers to enter data faster and easier than writing reports by hand. It also facilitates creating summary information about lesions for the farmer that can be used to decrease lameness in their herds (DeFrain et al., 2013). Furthermore, from a data analysis perspective, electronic record keeping of foot lesions can be used for benchmarking and genetic improvement (Chapinal et al., 2013; Kofler, 2013), whereas from a research standpoint, it increases accuracy and efficiency of data collection by reducing errors due to transcription and helps in standardizing lesion diagnoses (Shearer and Van Amstel, 2013).

All hoof trimmers were professionally trained in hoof trimming. Regardless, hoof trimmers attended 2 training sessions to standardize foot lesion data collection based on internationally recognized nomenclature. A limitation is that intra- and interobserver agreements for lesion recognition among hoof trimmers were not evaluated. However, the correlation (ICC) of foot lesion observations within hoof trimmers was low. Therefore, little evidence suggested that hoof trimmers overrepresented certain lesions. Nevertheless, a degree of bias is expected because foot lesion diagnosis and recording is based on visual inspection.

\section{CONCLUSIONS}

The prevalence of foot lesions differed among housing types, with cows housed in deep-bedded packs being the least affected. Digital dermatitis was the most common foot lesion in all housing types and throughout all parities and stages of lactation, followed by sole ulcers and white line disease. Within-herd prevalence varied greatly; notwithstanding, for all lesions, some herds had a prevalence of zero, which provides good evidence that low prevalence of foot lesions is achievable. Preventive measures for the control of digital dermatitis merit emphasis, especially in primiparous cows and on farms with exercise areas. Given that the vast majority of dairy farms in Alberta are freestalls with zero-grazing, improving housing environment by providing a deepbedded area for older cows in mid or late lactation could reduce prevalence of claw horn lesions. We inferred that foot lesion data recorded by hoof trimmers provided useful information not only for developing effective foot health programs at the herd level, but also for disease surveillance and genetic improvement at regional and national levels.

\section{ACKNOWLEDGMENTS}

The authors thank participating hoof trimmers and farmers for making this study possible. We are especially grateful for the contributions of Melodie Chan, Christoph Muelling, and Paul Greenough. We also thank John Kastelic (Department of Production Animal Health, University of Calgary, AB, Canada) for editing this manuscript and Diego Nobrega for his input and advice in the statistical analyses. Keith Sather and Gretchen Demulling from KS Dairy Consulting provided invaluable support in the use of Hoof Supervisor data collection systems. This study was funded by Alberta Milk (Edmonton, AB, Canada), Alberta Farm Animal Care (High River, AB, Canada), and Agriculture and Agri-Food Canada, as part of the Canadian Agricultural Adaptation Program.

\section{REFERENCES}

Barkema, H. W., J. D. Westrik, K. A. S. van Keulen, Y. H. Schukken, and A. Brand. 1994. The effects of lameness on reproductive performance, milk production and culling in Dutch dairy farms. Prev. Vet. Med. 20:249-259.

Barker, Z. E., J. R. Amory, J. L. Wright, S. A. Mason, R. W. Blowey, and L. E. Green. 2009. Risk factors for increased rates of sole ulcers, white line disease, and digital dermatitis in dairy cattle from twenty-seven farms in England and Wales. J. Dairy Sci. 92:1971-1978.

Bell, N. J., M. J. Bell, T. G. Knowles, H. R. Whay, D. J. Main, and A. J. F. Webster. 2009. The development, implementation and testing of a lameness control programme based on HACCP principles and designed for heifers on dairy farms. Vet. J. 180:178-188.

Bicalho, R. C., V. S. Machado, and L. S. Caixeta. 2009. Lameness in dairy cattle: A debilitating disease or a disease of debilitated cattle? A cross-sectional study of lameness prevalence and thickness of the digital cushion. J. Dairy Sci. 92:3175-3184.

Bicalho, R. C., and G. Oikonomou. 2013. Control and prevention of lameness associated with claw lesions in dairy cows. Livest. Sci. 156:96-105.

Bruijnis, M. R. N., B. Beerda, H. Hogeveen, and E. N. Stassen. 2012. Assessing the welfare impact of foot disorders in dairy cattle by a modeling approach. Animal 6:962-970.

Bruijnis, M. R. N., H. Hogeveen, and E. N. Stassen. 2010. Assessing economic consequences of foot disorders in dairy cattle using a dynamic stochastic simulation model. J. Dairy Sci. 93:2419-2432.

Canadian Dairy Information Centre. 2016. Dairy facts and figures. Accessed April 15, 2016. http://www.dairyinfo.gc.ca.

Capion, N., S. M. Thamsborg, and C. Enevoldsen. 2008. Prevalence of foot lesions in Danish Holstein cows. Vet. Rec. 163:80-86.

Chapinal, N., A. M. de Passillé, D. M. Weary, M. A. G. von Keyserlingk, and J. Rushen. 2009. Using gait score, walking speed, and lying behavior to detect hoof lesions in dairy cows. J. Dairy Sci. 92:4365-4374.

Chapinal, N., A. Koeck, A. Sewalem, D. F. Kelton, S. Mason, G. Cramer, and F. Miglior. 2013. Genetic parameters for hoof lesions 
and their relationship with feet and leg traits in Canadian Holstein cows. J. Dairy Sci. 96:2596-2604.

Cook, N. B., and K. V. Nordlund. 2009. The influence of the environment on dairy cow behavior, claw health and herd lameness dynamics. Vet. J. 179:360-369.

Cramer, G., K. D. Lissemore, C. L. Guard, K. E. Leslie, and D. F. Kelton. 2008. Herd- and cow-level prevalence of foot lesions in Ontario dairy cattle. J. Dairy Sci. 91:3888-3895.

Cramer, G., K. D. Lissemore, C. L. Guard, K. E. Leslie, and D. F. Kelton. 2009a. The association between foot lesions and culling risk in Ontario Holstein cows. J. Dairy Sci. 92:2572-2579.

Cramer, G., K. D. Lissemore, C. L. Guard, K. E. Leslie, and D. F. Kelton. 2009b. Herd-level risk factors for seven different foot lesions in Ontario Holstein cattle housed in tie stalls or free stalls. J. Dairy Sci. 92:1404-1411.

DeFrain, J. M., M. T. Socha, and D. J. Tomlinson. 2013. Analysis of foot health records from 17 confinement dairies. J. Dairy Sci. 96:7329-7339.

Espejo, L. A., M. I. Endres, and J. A. Salfer. 2006. Prevalence of lameness in high-producing Holstein cows housed in freestall barns in Minnesota. J. Dairy Sci. 89:3052-3058.

Ettema, J. F., and S. Ostergaard. 2006. Economic decision making on prevention and control of clinical lameness in Danish dairy herds. Livest. Sci. 102:92-106.

Fjeldaas, T., A. M. Sogstad, and O. Østerås. 2006. Claw trimming routines in relation to claw lesions, claw shape and lameness in Norwegian dairy herds housed in tie stalls and free stalls. Prev. Vet. Med. 73:255-271.

Garbarino, E. J., J. A. Hernandez, J. K. Shearer, C. A. Risco, and W. W. Thatcher. 2004. Effect of lameness on ovarian activity in postpartum Holstein cows. J. Dairy Sci. 87:4123-4131.

Green, L. E., V. J. Hedges, Y. H. Schukken, R. W. Blowey, and A. J. Packington. 2002. The impact of clinical lameness on the milk yield of dairy cows. J. Dairy Sci. 85:2250-2256.

Green, L. E., J. N. Huxley, C. Banks, and M. J. Green. 2014. Temporal associations between low body condition, lameness and milk yield in a UK dairy herd. Prev. Vet. Med. 113:63-71.

Greenough, P. R. 2007. Bovine laminitis and lameness: A hands-on approach. W.B. Saunders Company, Philadelphia, PA.

Greenough, P. R. 2010. The Alberta Dairy Hoof Health Project: lesion severity scoring guide. AgroMedia International Inc. Accessed April 15, 2016. http://dairyhoofhealth.info/Lesion-SeverityGuide-v0.7.pdf.

Haufe, H. C., L. Gygax, B. Wechsler, M. Stauffacher, and K. Friedli. 2012. Influence of floor surface and access to pasture on claw health in dairy cows kept in cubicle housing systems. Prev. Vet. Med. 105:85-92.

Hernandez-Mendo, O., M. A. G. von Keyserlingk, D. M. Veira, and D. M. Weary. 2007. Effects of pasture on lameness in dairy cows. J. Dairy Sci. 90:1209-1214.

Holzhauer, M., C. J. M. Bartels, B. H. P. van den Borne, and G. van Schaik. 2006a. Intra-class correlation attributable to claw trimmers scoring common hind-claw disorders in Dutch dairy herds. Prev. Vet. Med. 75:47-55.

Holzhauer, M., B. Brummelman, K. Frankena, and T. J. Lam. 2012. A longitudinal study into the effect of grazing on claw disorders in female calves and young dairy cows. Vet. J. 193:633-638.

Holzhauer, M., C. Hardenberg, and C. J. M. Bartels. 2008. Herd and cow-level prevalence of sole ulcers in The Netherlands and associated-risk factors. Prev. Vet. Med. 85:125-135.

Holzhauer, M., C. Hardenberg, C. J. M. Bartels, and K. Frankena. 2006b. Herd- and cow-level prevalence of digital dermatitis in the Netherlands and associated risk factors. J. Dairy Sci. 89:580-588.

International Lameness Committee. 2008. Dairy claw lesion identification. In Proc. 15th Int. Symp. 7th Conf. Lameness in Ruminants, Kuopio, Finland. Savonia University of Applied Sciences, Kuopio, Finland.
Kelton, D. F., K. D. Lissemore, and R. E. Martin. 1998. Recommendations for recording and calculating the incidence of selected clinical diseases of dairy cattle. J. Dairy Sci. 81:2502-2509.

Kofler, J. 2013. Computerised claw trimming database programs as the basis for monitoring hoof health in dairy herds. Vet. J. 198:358-361.

Laven, R. A., and D. N. Logue. 2007. The effect of pre-calving environment on the development of digital dermatitis in first lactation heifers. Vet. J. 174:310-315.

Manske, T., J. Hultgren, and C. Bergsten. 2002a. Hoof lesions and lameness in Swedish dairy cattle: Prevalence, risk factors, effects of claw trimming and consequences for productivity. $\mathrm{PhD}$ Thesis. Sveriges Lantbruksuniversitet, Sweden.

Manske, T., J. Hultgren, and C. Bergsten. 2002b. Prevalence and interrelationships of hoof lesions and lameness in Swedish dairy cows. Prev. Vet. Med. 54:247-263.

Murray, R. D., D. Y. Downham, M. J. Clarkson, W. B. Faull, J. W. Hughes, F. J. Manson, J. B. Merritt, W. B. Russell, J. E. Sutherst, and W. R. Ward. 1996. Epidemiology of lameness in dairy cattle: description and analysis of foot lesions. Vet. Rec. 138:586-591.

Potterton, S. L., N. J. Bell, H. R. Whay, E. A. Berry, O. C. D. Atkinson, R. S. Dean, D. C. J. Main, and J. N. Huxley. 2012. A descriptive review of the peer and non-peer reviewed literature on the treatment and prevention of foot lameness in cattle published between 2000 and 2011. Vet. J. 193:612-616.

Sanders, A. H., J. K. Shearer, and A. De Vries. 2009. Seasonal incidence of lameness and risk factors associated with thin soles, white line disease, ulcers, and sole punctures in dairy cattle. J. Dairy Sci. 92:3165-3174

Shearer, J., P. J. Plummer, and J. A. Schleining. 2015. Perspectives on the treatment of claw lesions in cattle. Veterinary Medicine: Research and Reports. 6:273-292.

Shearer, J., and S. Van Amstel. 2013. Manual of Foot Care in Cattle. 2nd ed. Hoard's Dairyman, Fort Atkinson, WI.

Shearer, J. K., and S. R. van Amstel. 2008. Toe lesions in dairy cattle. Pages 47-55 in Proc. 46th Annual Florida Dairy Production Conference. University of Florida Dairy Extension, Gainesville, Florida.

Sogstad, A. M., T. Fjeldaas, O. Østerås, and K. P. Forshell. 2005. Prevalence of claw lesions in Norwegian dairy cattle housed in tie stalls and free stalls. Prev. Vet. Med. 70:191-209.

Solano, L., H. W. Barkema, E. A. Pajor, S. Mason, S. J. LeBlanc, J. C. Zaffino Heyerhoff, C. G. R. Nash, D. B. Haley, E. Vasseur, D. Pellerin, J. Rushen, A. M. de Passillé, and K. Orsel. 2015. Prevalence of lameness and associated risk factors in Canadian HolsteinFriesian cows housed in freestall barns. J. Dairy Sci. 98:6978-6991.

Somers, J. G., K. Frankena, E. N. Noordhuizen-Stassen, and J. H. M. Metz. 2003. Prevalence of claw disorders in Dutch dairy cows exposed to several floor systems. J. Dairy Sci. 86:2082-2093.

Somers, J. G., K. Frankena, E. N. Noordhuizen-Stassen, and J. H. M. Metz. 2005a. Risk factors for interdigital dermatitis and heel erosion in dairy cows kept in cubicle houses in The Netherlands. Prev. Vet. Med. 71:23-34.

Somers, J. G., K. Frankena, E. N. Noordhuizen-Stassen, and J. H. M. Metz. 2005b. Risk factors for digital dermatitis in dairy cows kept in cubicle houses in The Netherlands. Prev. Vet. Med. 71:11-21.

Tadich, N., E. Flor, and L. Green. 2010. Associations between hoof lesions and locomotion score in 1098 unsound dairy cows. Vet. J. 184:60-65.

Tarlton, J. F., D. E. Holah, K. M. Evans, S. Jones, G. R. Pearson, and A. J. F. Webster. 2002. Biomechanical and histopathological changes in the support structures of bovine hooves around the time of first calving. Vet. J. 163:196-204.

Toussaint Raven, E. 1985. Cattle Footcare and Claw Trimming. Farming Press, Ipswich, UK. 